\title{
An Empirical Research of Factors Influencing the Decision-Making of Chinese Online Shoppers
}

\author{
Hui Chen ${ }^{1}$ and Yuanzhi $\mathrm{Li}^{2}$ \\ 1 Economic \& Management School, Beijing University of Posts \& \\ Telecommunications. No. 10, Xitucheng Street, Haidian District, Beijing. \\ chen-hui@vip.sina.com. \\ 2 Economic \& Management School, Beijing University of Posts \& \\ Telecommunications, liyuanzhi2008@163.com
}

\begin{abstract}
As the number of Chinese online shoppers increases, it becomes increasingly important to understand their decision-making processes. The factors that influenced the purchasing behaviour of 190 online shoppers were studied. Our research showed that the ease of use of a website, the quality of product information provided the entertainment value and perceived trust all greatly enhanced the satisfaction of online shoppers and significantly influenced their buying intentions.
\end{abstract}

\section{Introduction}

E-commerce is developing rapidly in China. By June 2006 it was estimated that 30 million Chinese citizens had made online purchases and the number of regular online shoppers had grown by $50 \%$ compared to the same period of the previous year. According to a report issued by CNNIC[1], transactions on the $\mathrm{B} 2 \mathrm{C}$ market in the second quarter of 2006 totalled 907,400,000 RMB Yuan (about 113,200,000 dollars), up $6.2 \%$ against the first quarter and up $72.1 \%$ against the same period of the previous year.

E-commerce is a relatively new business mode. The factors, which influence the buying intentions of online consumers, are different to those that influence traditional consumers. Some foreign studies have already looked into the decisionmaking of online shoppers, but, so far, Chinese researchers have paid little attention to this field. China's unique social-cultural environment along with the recent rapid development of Chinese E-commerce markets combine to provide

Please use the following format when citing this chapter:

Chen, H., Li, Y., 2007, in IFIP International Federation for Information Processing, Volume 25I, Integration and Innovation Orient to E-Society Volumel, Wang. W. (Eds), (Boston: Springer), pp. 202-210. 
Chinese online shoppers with their own particular characteristics regarding their decision-making. This study empirically assesses the factors that influence the decision-making of Chinese online shoppers.

\section{Conceptual Framework}

Studies into online shopping decision-making may use either purchasing behaviour or buying intention as dependent variables. This research uses buying intention as the dependent variable.

On the basis of previous research [2,3], factors relating to the individual consumer, to the product being purchased and to the retail website were identified as being those which influenced the buying intention. Factors relating to the individual consumer include: attitude, sense of control, perceived risks, previous experiences, self-confidence, creativity, cultural background and demographic characteristics. Factors relating to the product include: the product type, price and perceived quality. Factors relating to the retail web site include the interface design of the website, the size and reputation of the company, the ease and speed of use of a website, and the frequency with which information on the website is updated.

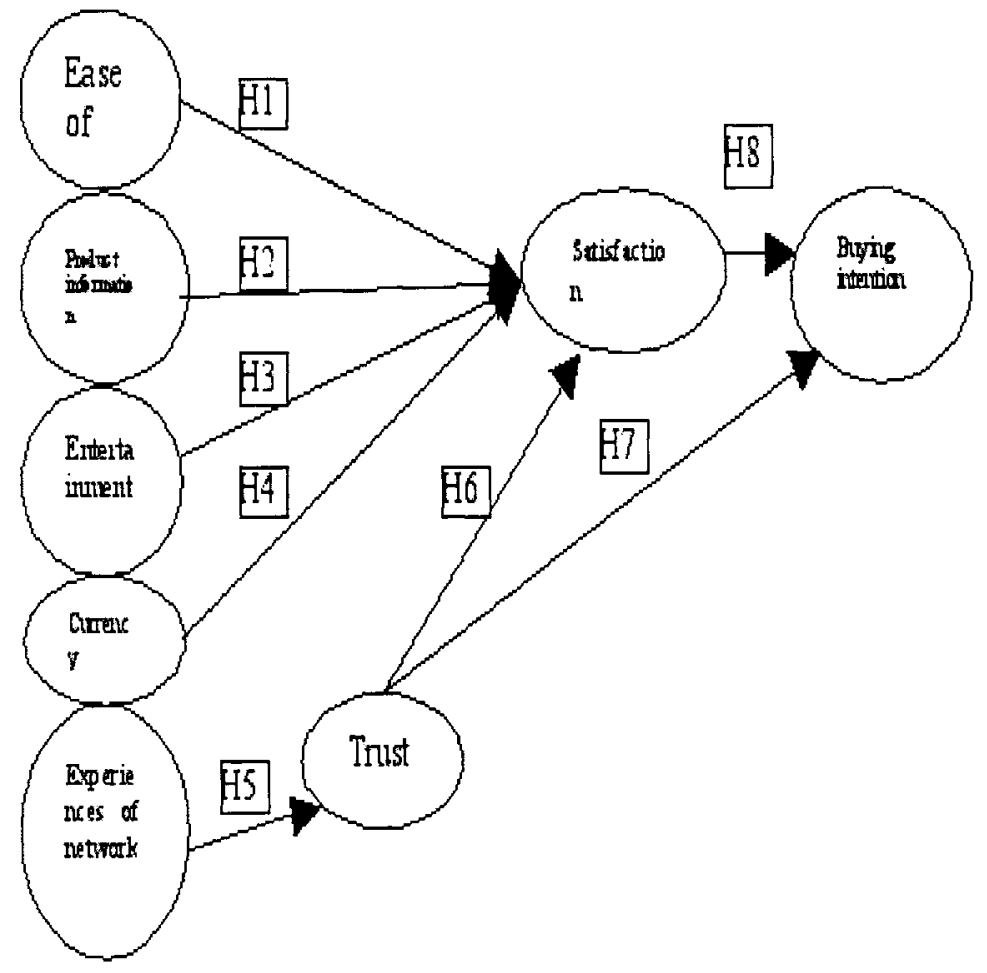

Fig.1. Research Model 
Concentrating on B2C e-commerce, we took into account the current state of Chinese online shopping and the results of previous studies. This study focuses on factors that relate to the online shopping websites themselves and to factors that relate to the individual consumer. Factors relating to the online shopping websites include ease of use, product information, and entertainment and currency. The individual factors are the trust of consumers in the retail website and Experience of network. The factors relating to the retail websites and to Experience of network are independent variables. Trust and consumer satisfaction with the retail websites are mediate variables. The buying intention of the consumer is used as the dependent variable in the construction of the research model (Figure 1).

\subsection{Definitions and Hypotheses}

\subsubsection{Website Factors}

Ease of Use. The ease of website navigation, organizational structure, clear pricing and simple purchase procedures.

Several studies have reported a positive relationship between ease of use and consumer satisfaction $[4,5]$. Other studies showed that ease of use also enhanced consumer trust [6], shopping intention [7] and attitude towards online shopping [8]. In this work, we propose:

Hypothesis 1 (H1): Ease of Use influences the Satisfaction of online shoppers with a website.

Product Information. The product quality, stock levels and the way in which information about the available products and services is presented on a website.

Syzmanski and Hise [4] reported a positive correlation between product information and consumer satisfaction with a web site. Other studies demonstrated that product information influenced the buying intention of consumers [9], their attitude towards online shopping [10], and the amount of online shopping [11]. In this work, we propose:

Hypothesis 2 (H2): Product Information influences the Satisfaction of online shoppers with a website.

Entertainment. Elements of a website which make the online buying experience more interesting and more enjoyable.

Other researchers have shown that entertainment influenced the satisfaction of consumers towards a website [12], and also influenced their attitude towards online shopping [8]. In this work, we propose:

Hypothesis 3 (H3): Entertainment influences the Satisfaction of online shoppers with a website.

Currency. Product information, prices and other relevant information on a website is updated promptly.

Studies by Fogg [6] and by Chen and Dhillon [7] reported that websites with up to date information are more trusted than those that are updated less frequently. Other studies concluded that the speed of updating influenced the satisfaction of consumers with a website and influenced their buying intention. In this work, we propose: 
Hypothesis 4 (H4): Currency influences the Satisfaction of online shoppers with a website.

\subsubsection{Individual Factors}

Experience of network. Previous experience of using the Internet, frequency of use and degree of computer literacy.

Korgaonkar and Wolin [13] reported that experienced online shoppers were more likely to play down security issues and seek information, convenience, and economic value whilst Ward and Lee [14] found that online experience increases search proficiency. Yang and Huang [5] found that experienced online shoppers focused less on security issues but more on reliability, personalization, and ease of use. Finally, the Pew Foundation [15] found increased levels of online shopping and spending amongst experienced Internet users. In this work, we propose:

Hypothesis 5 (H5): Experience of network influences how much an online shopper will Trust a website.

Trust. The degree of confidence that the consumer has in the Internet in general and in the reliability and sincerity of the shopping website in particular.

It was found [16], that if a consumer trusted a particular website they would search for product information from that website more frequently and they would be willing to provide the necessary personal data to the web site in order to make a purchase. We also believe that if a customer trusts a particular website, they will be more likely to use and make purchases from that website in the future.

In this work, we propose:

Hypothesis 6 (H6): Trust in a website influences the Satisfaction with the website.

and

Hypothesis 7 (H7): Trust in a website influences the buying intention.

Satisfaction. Degree of contentment. How happy the consumer is with the shopping experience.

Sutton and Hallett [17] proposed that past experiences influence future actions. The satisfaction of online consumers with a website will influence the current buying intention and will influence their future use of that website and subsequent buying intentions. In this work, we propose:

Hypothesis 8 (H8): Satisfaction with a website as a mediate variable influences the buying intention.

\section{Research Methods}

\subsection{Object}

According to the Statistics Report on Chinese Internet Development [1], students make up $36.2 \%$ of all Internet users in China. Hoffman and Novak [16] found that online shoppers were mainly composed of highly educated young people with high 
incomes. Accordingly, all of our subjects had received a university or above level of education. Many of the subjects were still university students and all of them had previous experience of using the Internet. 193 questionnaires were distributed and collected, $190(98.4 \%)$ of which were included in this study. $55.3 \%$ of the subjects were male and $44.7 \%$ were female.

\subsection{Procedure}

The two websites (website $A$ and website $B$ ) used in this research study were reallife commercial websites rather than simulated sites. Both of the chosen websites sold a similar range of products that related to the everyday needs of the subjects. The subjects were instructed to buy articles such as books and CD's and given a fixed budget to carry out their purchases. The testing procedure was conducted in a computer laboratory in which each computer was configured identically. Each subject completed the test procedure independently. The subject were told to decide which products they would like to purchase and to spend about 15 minutes browsing the first website for the appropriate product information. After 10 minutes rest period, the subject was told to repeat the search procedure on the second website. The subjects were then told to make a comparison between the two websites and to decide which one they would choose to make their purchases. After making their purchase decisions, each of the subjects was asked to fill in a questionnaire relating to their browsing and purchase experiences on the chosen web sites. The subject's required about 45 minutes to complete the whole test procedure.

In this study, the subjects were asked to state which website they preferred to make purchases from and to then complete questionnaires which were used to evaluate their buying intention. The online shopping exercise gave us useful insights into factors relating to website design and provided the subjects with a recent online buying experience to call upon when filling in the questionnaire.

\subsection{Measurements}

The measuring indices of the major variables studied in this work were adapted from those used recently in the research literature. All of the questionnaires used 5-point Likert scales. Measuring questionnaires included: Ease of Use, 4 items, as developed by Lynch and Ariely [18]; Entertainment: 4 items, as developed by Paul [19]; Currency: 4 items, as developed by Fogg [8] ; Product Information: 4 items, developed by Paul [19]; Trust: 4 items, developed by Joey [20]; Buying intention: 3 items, as developed by Chen and Wells [21]; Satisfaction: 5 items, measurement procedure developed for this work. Experience of network; 15 items, measurement procedure developed for this work. 


\section{Research Results}

\subsection{Questionnaire Reliability Analysis}

Alpha (Cronbach $\alpha$ ) coefficient is used to test the internal reliability of the measuring questionnaire. "Ease of use", $\alpha=0.7237$, "Product information", $\alpha=0.6992$, "Entertainment", $\alpha=0.6542$, "Currency", $\alpha=0.7014$, "Experiences of using network", $\alpha=0.6845$, "Trust", $\alpha=0.7123$, "Satisfaction", $\alpha=0.7846$, "Buying intention", $\alpha=0.7645$. Generally speaking, it is acceptable when alpha value is higher than 0.6 .

\subsection{Path Analysis}

Path analysis of SPSS 11.5 was used to verify our research model and hypotheses. The data obtained from the completed questionnaires supported most of our hypotheses.

$\mathrm{H} 1, \mathrm{H} 2, \mathrm{H} 3, \mathrm{H} 5, \mathrm{H} 6$ and $\mathrm{H} 8$ were supported by the results of the data analysis.

Ease of use, product information, entertainment, and trust all influenced the satisfaction of online shoppers with a website. Experience of network influenced trust. The satisfaction of online consumers with a website significantly influenced their buying intention.

Hypotheses $\mathrm{H} 4$ and $\mathrm{H} 7$ were rejected. Currency did not have a definite influence over consumer satisfaction. Trust did not have a definite influence over the buying intention.

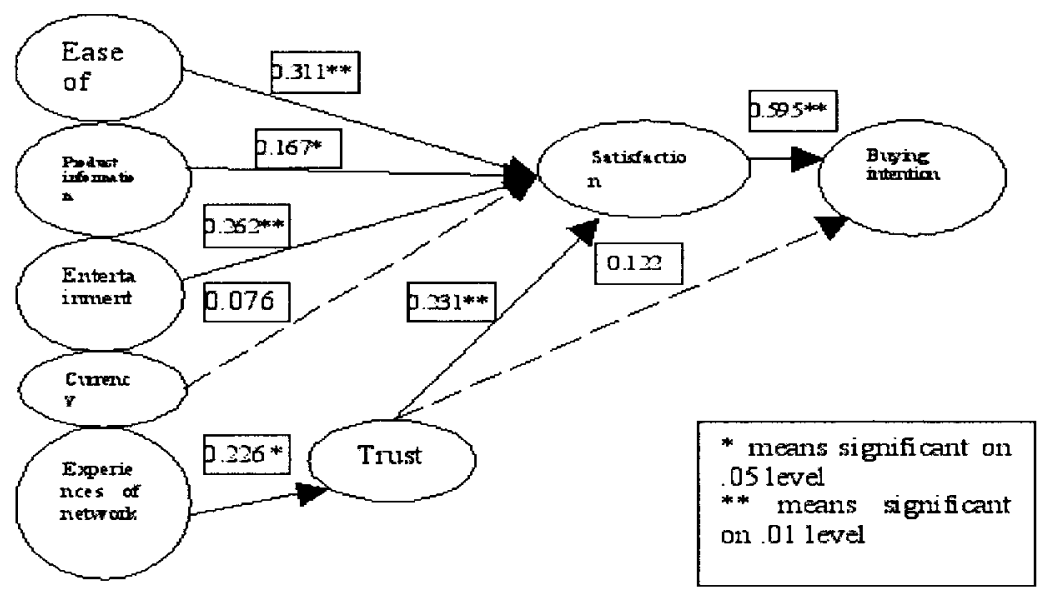

Fig .2. Result of Path Analysis 


\section{Discussion and Managerial Implications}

\subsection{Discussion}

Hypotheses $\mathrm{H} 1, \mathrm{H} 2, \mathrm{H} 3, \mathrm{H} 5, \mathrm{H} 6$ and $\mathrm{H} 8$ were supported by analysis of the completed questionnaires.

Our results supported the findings of of previous research into the buying habits of online consumers. Paul [19] postulated that easily navigable web pages, clear organizational structure, and simple purchasing procedures were necessary to satisfy the needs of online consumers. Syzmanski and Hise [4] demonstrated a strong positive correlation between product information and the satisfaction of online consumers. Coyle and Thorson [12] also showed that entertainment had an influence on a consumer's satisfaction with a website. A consumer's satisfaction with a website had a strong influence on their ultimate buying intention.

Hypotheses $\mathrm{H} 4$ and $\mathrm{H} 7$ were rejected after analysis of the completed questionnaires.

We found that currency did not have a definite influence over consumer's satisfaction. This finding opposed our hypothesis $\mathrm{H} 4$ and was in contradiction to the results of Paul [19]. Whilst well developed in a number of economically advanced countries, e-commerce is a recent phenomenon in China and still something of a novelty. In a separate study [22], we found that many consumers browse and shop online to satisfy their curiosity.

We discovered that trust did not have a definite influence over the buying intentions of consumers. This went against our hypothesis $\mathrm{H} 7$. We believe that this is a characteristic peculiar to the decision-making of online shoppers, although we cannot discount that this finding may be related to the use of large numbers of students among our research subjects. University students are frequent users of the Internet and shop online more often than people from other sectors of society. These young consumers may be less concerned with trust issues than other online shoppers. This particular topic is worthy of further research.

Our results showed that currency did not have a significant influence upon consumer satisfaction with a website and that trust did not have a significant influence on the buying intention. These findings are opposite to similar researches in other countries. China has a unique economic, political and cultural environment. The way in which Chinese consumers make decisions in an E-commerce environment may also be unique.

\subsection{Managerial Implications}

Ease of use is a variable that significantly influenced the satisfaction of online shoppers. The two web sites used in this study did not differ greatly in terms of interface design, product category and distribution system, yet $74.7 \%$ of the subjects chose to make their purchases from website A. Website A possessed a practical guide system, had detailed product descriptions and had a straightforward 
method for making purchases. Website A was rated much more user-friendly than website B. Online retailers should strive to improve the ease of use of their websites and to increase the quality of the services they offer in order to ensure the satisfaction of their consumers and obtain a favourable buying intention. Online retailers must also aim to get repeat business from existing consumers and market themselves to attract new consumers.

Product Information also had a positive influence on the satisfaction of online shoppers. In particular, consumers expect to have complete and up to date product specifications to enable them to compare different products and different brands. Web sites that accommodated the information needs of consumers were evaluated more favourably.

Entertainment had a significant impact upon the satisfaction of online shoppers. We found that the subjects were attracted to extraneous design elements not directly related to the purchasing process. One method of increasing the average time spent on a general retail website is to include peripheral elements, such as highresolution graphics, music and humorous characters. Entertainment enhances the browsing experience of low involvement shoppers.

Trust is an important factor in determining the satisfaction of online shoppers with a website. Our research was unable to verify a direct link between trust and the buying intention, although we did find that trust influenced satisfaction, which subsequently influenced the buying intention. Our subjects voiced concerns relating to Internet and credit card security, spam, identity fraud and the misuse of personal data. Given our finding that trust has a large influence on the satisfaction of online shoppers with a website, it is clear that online retailers must work hard to create and maintain trust in their business.

In conclusion, increasing numbers of Chinese citizens are choosing to make online purchases and E-commerce is making increasingly important contributions to the Chinese economy, yet the decision making behaviour of Chinese online consumers may be different to those from other countries. Thus, businesses wishing to be successful in the Chinese E-commerce market are advised to take into account the particular needs of Chinese consumers. The unique decision making behaviour of Chinese consumers, both online and offline, is deserving of further study.

\section{References}

1. CNNIC. Statistics Report on Chinese Internet Development in 2006, People Posts \& Telecommunications Press, Beijing(2006).

2. H.R. Li, K. Cheng, G. Martha and C. Russel, The Impact of Perceived Channel Utilities Shopping Orientations and Demographics on the Consumer Online Buying Behavior, Journal of Computer-Mediated Communication, 5(2),108-109 (1999).

3. V. Swaminathan, E. Lepkowska-White and B.P. Rao, Browsers or Buyers in Cyberspace? An Investigation of Factors Influencing Electronic Exchange, Journal of Computer Mediated Communication, 12(1), 77-79 (1999). 
210 An Empirical Research of Factors Influencing the Decision-Making of Chinese

Online Shoppers

4. D.M. Szymanski and R. T. Hise, e-Satisfaction: an initial examination, Journal of Retailing , 76(2), 309-322(2000).

5. Z. Yang, R.T. Peterson andL. Huang, Taking the pulse of internet pharmacies, Marketing Health Services ,21(2), 4-10 (2001).

6. B.J. Fogg, J. Marshall, 0. Laraki, A. Osipovich, C.Varma, N. Fang, J. Paul,A. Rangnekar, J. Shon, P.,Treinen and M. Swani, What makes web sites credible? A report on a large quantitative study, Persuasive Technology Lab, 11(1), 61-68(2001).

7. S. Chen and G.. Dhillon, Interpreting dimensions of consumer trust in e-commerce, Information Technology and Management ,4(2-3), 303-318(2003).

8. S. L. Jarvenpaa, and P. A. Todd, Electronic Marketing and the Consumer. Edited by R. S. Peterson. Thousand Oaks, CA: Sage Publications(1997).

9. N. Donthu, Does your web site measure up?, Marketing Management, 10(4), 2932(2001).

10. L.R. Vijayasarathy andJ.M. Jones, Print and internet catalog shopping: assessing attitudes and intentions, Internet Research, 10(3), 191-202(2000).

11. S. Bellman, G.L. Lohse and E.J. Johnson, Predictors of online buying behavior. Association for Computing Machinery, Communications of the ACM,42(12), 32-38(1999).

12. J.R. Coyle andE. Thorson, The effects of progressive levels of interactivity and vividness in web marketing sites, Journal of Advertising ,41(3), 65-77 (2001).

13. P.K. Korgaonkar and L.D. Wolin, A multivariate analysis of web usage. Journal of Advertising Research ,39, 53-68(1999).

14. M.R. Ward and M.J. Lee, Internet shopping, consumer search, and product branding, Journal of Product \& Brand Management ,9(1), 6-20.22(2000).

15. Pew Foundation. http://www.pewintemet.org/reports.[2007-1-7].

16. C.C Hoffman and CT.P. Novak, Marketing In hypermedia computer-mediated environments, Conceptual foundations Journal of Marketing ,60(3), 50-80(1996).

17. S.R. Sutton and C. Candhallett, Understanding seat-belt intentions and behavior: a decision êmaking approach, Journal of applied Social Psychology,(19), 1310-1325(1989).

18. J. G. Lynch and D. Ariely, Wine online: search costs affect competition on price, quality and distribution, Marketing Science 19 (Winter), 83-103(2000).

19. S. Paul, Factors that affect attitude toward a retail web site, Journal of Marketing Theory and Practice 2005 (Winter), 40-51, (2005).

20. F. Joey and George, Influences on the intent to make Internet purchases, Internet Research Electronic Networking Applications and Policy, 12(2), 165-180(2002).

21. Q. Chen and W. D. Wells, Attitude toward the site, Journal of Advertising Research,40(5), 27-37(1999).

22. H. Chen and Y.Z. Li, The research of motivation of online shoppers (in press) (2007). 